\title{
Humanitarian Cooperation between China and Countries in Sub-Saharan Africa*
}

\author{
Anastasia Zabella \\ Faculty of Humanities and Social Sciences \\ Peoples' Friendship University of Russia \\ 10/2 Miklukho-Maklay Str. \\ Moscow, Russia \\ E-mail: zabella-rudn@yandex.ru
}

\begin{abstract}
Humanitarian cooperation is perceived as a key to boost comprehensive partnership between China, the world's largest developing country, and countries in subSaharan Africa. It is not a secret that Africa has the highest number of developing countries, so it is one of the reasons, why China increases cooperation with the continent. The article highlights the main directions of China's humanitarian cooperation with countries in sub-Saharan Africa. In the author's opinion, it includes culture, education, science and the humanitarian missions of the PRC. In particular, the paper highlights the importance of public diplomacy of China. The author of the article affirms that the Confucius Institutes plays an indispensable role in China and the countries in subSaharan Africa's collaboration, which includes education and cooperation between states and represents a new model of South-South multilateral relations. The author calls upon China and the African countries for broadening humanitarian cooperation.
\end{abstract}

Keywords-culture; science; humanitarian missions; Confucius Institutes; public diplomacy

\section{INTRODUCTION}

The humanitarian relations can easily deepen the confidence between states, and often do. Alongside economic, military and political power, the influence of any states depends on their cultural power, which can be described as a tool of public diplomacy. In this article, the author considers such areas of interstate cooperation as: culture, education, science, humanitarian missions of the PRC. The above spheres are the basic components in the implementation of the PRC foreign policy tasks in the field of "soft power".

The first China's White Paper on Foreign Aid dated 2011 headlining that Chins has consolidated friendly relations and economic and trade cooperation with other developing countries, promoted South-South cooperation and contributed to the common development of mankind.

*This research was carried out with the financial support of the Russian Foundation for Basic Research in the framework of the scientific project RFBR-CASS No. 17-27-21002 "Russian and Chinese aid to Asian and African countries: comparative analysis and perspectives of coordination".
It should be noted, that the White Paper on China's Foreign Aid dated 2011, the 2013 White Paper on ChinaAfrica Economic and Trade Cooperation illustrate its related to skills and education assistance, in addition to "human resources development and educational cooperation with Africa" adjudged as a single concept.

As we turn now to examine briefly the main principles used by Chinese Communist Party in the sphere of extending African's educational potential through cooperation, we should note that mutual learning and benefits are important aspects of the collaboration. At the same time many African states seek a partner that, unlike the West, does not worry about democracy and transparency.

\section{THE ROLE OF PUBLIC DIPLOMACY IN THE ForEIGN POLICY OF THE PEOPLE'S REPUBLIC OF CHINA}

Talking of "soft power" it is worth to emphasize that China since the beginning of the 21 st century started to express desire to become one of the leading states of the world and to realize its ambitions from the position of an insider.

In 2003, one of the well-known Chinese scientists Zhen Bijian at the meeting of the Boao's Forum made a proposal to use the "peaceful rise", whose idea was subsequently published in "Foreign Affairs"[1]. The main idea, according to Zhen Bijian, is reflected in the preservation of the idea of China's development along the road of socialism with Chinese characteristics, involvement in the processes of economic globalization, stabilization of the international situation.

The main components of this upgrade include:

- Dissemination of the image of the culture of your country from the positive side and demonstration of values that may be attractive to others;

- Social, economic and humanitarian assistance, as well as assistance in health and education;

- Balanced foreign policy, which should contribute to strengthening world economic and social stability [2]. 
The conceptual basis for the formation of an attractive image of China abroad is the Doctrine of China's Peaceful Rise, the Beijing Consensus and the Concept of a Harmonious World.

It is worth to pay attention to what is meant by the word harmonization. The theory of a harmonious peace was proposed by the Chairman of the PRC in 2003 and reflected the strategic thinking not only of the Secretary-General of the Communist Party of China, but of the entire Central Committee of the CPC [3]. From the scientific point of view, the theory of a harmonious world answers the general historical trend, the current international agenda. The essence of the theory boils down to multilateral cooperation, the promotion of development, the strengthening of peace, for which all actors of international relations must make "efforts to build a harmonious world with a long-term peace and common prosperity" ${ }^{\prime \prime}$.

$\mathrm{Hu}$ Jintao, in his theory, sees the key to solving international conflicts in building up interstate, multilateral and multi-level cooperation, which should be implemented in political, economic, educational, cultural, environmental and other spheres. On the achievement of a full-scale dialogue of states at all levels, on the basis of trust and the promotion of a common goal, the harmonization of the world will be achieved [4].

\section{THE ROLE OF THE CONFUCIUS INSTITUTE ON CHINA AND SUB-SAHARAN AFRICA COOPERATION EXPANDING MutuAl EDUCATIONAL COLLABORATION}

Following the unprecedented rise of the Chinese economy, strengthening of positions in the international arena, interest among foreigners in studying the Chinese language began to manifest. "Without understanding the words, you do not recognize people," are the words of Confucius that speak of the importance of learning a foreign language for a greater understanding of your partner. To date, China has taken a leading position in many areas, knowledge of the language is important for increasing communication between public and private individuals. Measures to popularize their language outside the country are able not only to increase the attractiveness of their country in the eyes of foreigners, but also to direct the train of thought of foreign citizens in a pre-determined way and with a clearly defined tonality that will allow to perceive any information under the necessary government angle.

In order to promote Chinese as a foreign language, to increase the interest of foreign citizens in Chinese culture, since 2004, China has begun to adopt the experience of Great Britain, Germany, France, and a number of other European countries in spreading and increasing the attractiveness of their language outside the state. This task falls within the competence of the Confucius Institutes and Confucius classes. The purpose of the above-mentioned Chinese centers for the study of the Chinese language is to spread and

\footnotetext{
Hu Jintao's speech at the Moscow State Institute of International Relations [Electronic resource]. URL:

http://russian.people.com.cn/95181/6823894.html (accessed: 12/09/2017).
}

popularize the language and culture abroad. The success of this project is backed by figures, so by the end of 2015,500 Confucius Institutes and over 1,000 classes of Confucius were opened in 134 countries $^{2}$.

In the development of the art of persuasion, attractiveness, and the creation of a positive image of China, the leadership of the PRC conducts continuous work in other areas.

Since the early 2000's, the 21 st century, the number of people studying Chinese is growing steadily. One can quote an extract from the speech of Xu Lin, Secretary-General of the Confucius Institute's headquarters, which reflects the importance and responsible attitude of the Chinese side in spreading the Chinese language and culture outside of China: "We plan that in 2020 the number of students studying the Chinese language will exceed 200 million people. This is the third indicator in the world. This alignment affects the Chinese voice in the international community" ${ }^{3}$.

The educational sphere has always been one of the highest priorities, as it is students who will in many respects influence the formation of the character and type of the future agenda, including in the sphere of interstate interaction. China provides a huge number of grants for foreigners, including African students. Recently, more and more students from the African continent began to appear in Chinese universities. Chinese education attracts students due to the high quality, low cost, and sometimes receiving a government grant and training at the expense of the Chinese side. As of the end of December 2015, 46 Confucius Institutes were opened in 32 African states, 23 Confucius classes began to function in 14 African states ${ }^{4}$. Such rapid dynamics of the opening of Chinese language centers once again confirms the important place of Africa in the foreign policy course of the PRC.

Speaking about cooperation in the field of education between the PRC and Angola, it should be noted that according to the Foreign Ministry of China at the end of 2014, the Chinese side allocated 202 grants to citizens of Angola for further education in Chinese universities due to the state budget of the PRC. At present, 534 foreign students from Angola are studying in China, of which 115 study under a grant- under a contract. In February 2015, the first Confucius Institute opened its doors in Angola.

In Nigeria, the Confucius Institute was also opened. By the end of 2014, China provided 555 scholarships to Nigerian citizens. In the same year, 2,979 students were trained in China, of which 251 were under a grant. Since 2010, 20 students have been trained in Nigerian universities to study the problems of Africa.

\footnotetext{
2 The site of the Chinese state agency for the dissemination of Chinese as a foreign language [Electronic resource]. URL:

http://www.hanban.edu.cn/confuciousinstitutes/node_10961.htm (accessed: 12/09/2017).

The site of the Central Television of China [Electronic resource]. URL: http://www.cntv.ru/2013/03/12/ARTI (accessed: 12/09/2017).

The site of the Chinese state agency for the dissemination of Chinese as a foreign language [Electronic resource]. URL: http://www.hanban.edu.cn/confuciousinstitutes/node_10961.htm (accessed: 12/09/2017)
} 
In June 2012, the first Confucius Institute in the country also opened its doors in the Congo. The Chinese side has allotted 616 grants to the citizens of the Congo for training in the PRC.

Cameroon, in turn, can demonstrate a rich experience of interaction in the field of education. A total of 584 students were trained in Chinese universities.

By the end of 2013, the total number of citizens of Equatorial Guinea who received higher education in Chinese universities is 362 people. In 2014, 661 students arrived in China for training, of which 171 under the grant. In October 2014, the first Confucius Institute was opened in Equatorial Guinea.

In 2014, the total number of students from Chad in Chinese universities reached 3,677 people, of which 329 received grants from the government of China. A number of universities in China and Chad cooperate in various educational projects. According to the Ministry of Foreign Affairs of China, at the end of 2014, China trained 2,291 specialists in the following areas: diplomacy, trade, economy, medicine, fisheries, communications, energy, etc.

The increase in those wishing to study Chinese is due to several reasons that will be considered below.

First, China's rapid economic growth drew the eyes of a foreign audience. Since 2000, the PRC has proclaimed a course of "going out", which had a positive impact on the development of economic growth and the state as a whole. From year to year, the People's Republic of China extends the list of trade and economic partners around the world. For some foreigners, knowledge of Chinese means the ability to find high-payed jobs. Knowledge of the Chinese language in many countries of the world has become a factor of career growth, promising employment.

Secondly, educational programs are important for the government of China. The consolidation of educational programs is the Confucius Institute, which is present in many countries of the world. Students who study Chinese in Confucius Institute are given the opportunity to go on a gratuitous internship in one of the universities of the PRC. In addition to educational activities, the Confucius Institute conducts scientific conferences, qualification exams on knowledge of the Chinese language, publishes research materials.

It is worth mentioning about "facade diplomacy". Thus, foreign students studying in Chinese universities receive more favorable conditions than Chinese citizens. The attitude of the Chinese side to foreigners, no doubt, is also a manifestation of the policy of improving the image of the state. Often, the attitude towards foreign citizens is better than that of Chinese citizens. This is confirmed not only at the legislative level, but also at the domestic level.

The PRC carries out educational projects for students from Africa, including from the oil-producing states of the continent in the specialties necessary for African states. Summarizing the above, it should be noted that the Chinese side, firstly, is preparing the most important personnel, without which the future development of the states of the African continent is impossible, and secondly, preparing international students in advance paves the way for closer cooperation in the long term.

Talking about science, it is worth emphasizing the fact that the Chinese side, from year to year, increases cooperation with the leading universities of African oilproducing states. On an ongoing basis, not only joint research projects are being conducted through the exchange of students, but also the adjustment of the educational programs of African universities to the standards of China.

In December 2015, the Chinese side announced the possibility of sending 30 groups of agronomist advisers to Africa in order to implement the project on "exemplary conduct of agricultural activities for the benefit of the people", the establishment of instruments for cooperation between scientific research institutions in the field of agriculture, the provision of humanitarian assistance to African countries. At the same time, a large number of specialists are sent from China to Africa, who are called upon to help African colleagues in various fields, both scientific and technical, and in production and humanitarian.

Such support and assistance from China is a stimulus for the development not only of science and education in the oilproducing states of Africa, but also the reduction of social tensions in the region, first, through literacy (significant number of Africans). Secondly - through the creation of new jobs.

The theory of the PRC on increasing its cultural influence in the world was developed in 2011 at the VI Plenum of the CPC Central Committee, where explanations were given on the mechanisms for its implementation as one of the effective means for achieving foreign policy goals, as well as improving the image component of the state. In 2011, a strategy was adopted on the development of "a powerful cultural state" [6].

The use of cultural levers in the foreign policy course of China is considered by the leadership of the state as an effective means of implementing the strategic course to transform the PRC into the leading world power by the middle of this century. In 2009, Hu Jintao praised the role of diplomacy in this task on one of the meetings, and also stressed the need to "make efforts to increase China's political influence, strengthen its economic competitiveness, develop the attractiveness of China's image and the moral appeal of its decisions" [7].

The implementation of the above-mentioned concept provides the resolution for emerging foreign policy issues by peaceful means, which involves non-confrontational and pragmatic diplomacy. The Chinese leadership has chosen this strategy to strengthen the position of the PRC in the international arena, as well as to increase the attractiveness of the "Celestial Empire". In this regard, the rate is made to prevent the threats, but not to counteract them.

It is worth emphasizing the role of the government in the implementation of this kind of task. To date, cultural appeal, as well as economic development, are in the priority of 
China's foreign policy strategy. The government identifies the following areas, which should be paid special attention in order spread Chinese influence:

1. There must be comprehensive transformations towards openness, prosperity, democracy, harmonization of society, and it is also important to put efforts in building a lawabiding civil society to create a favorable image in eyes of foreign citizens. Deng Xiaoping stressed in the last century that development should not rely solely on economic growth, it must find a balance in the economy, in politics, in culture, etc. Only after achieving such a balance can the state be comprehensively developed, the so-called "Chinese model" will evoke in people a sense of respect, which will lead to the desire of imitating such a model of China [8]. Deng Xiaoping's words can be confirmed by the following lines of Joseph Nye: "If what the government talks about is not one with an internal situation, then spreading the influence of the state abroad is a very complex undertaking" [9].

2. It is important to attach special importance to transformation and strengthening of the basic values, which requires a balance of three areas: economy, politics, society, the elimination of corruption, and the solution of imbalances between public and private companies. To strengthen the moral component of society, it is important to create a clear system of legal responsibility and guarantees, to promote good citizens in their endeavors, since they are an integral part of China's attractive image.

3. To create a positive image of the "Celestial Empire" one should not turn blind-eyed towards emerging problems, one should not forbid criticism, all efforts should be made to ensure that the image of the PRC is consistent with such features as: openness, confidence, tolerance, sincerity, responsibility. It is necessary to exert every effort to ensure that the world, step by step, accepts and follows the Chinese ideology of "harmonious society, harmonious peace".

4. It is worth learning and applying information and communication mechanisms to improve the image component, including with the involvement of internationally recognized public relations companies. So, the PRC has already launched a 24-hour television program, broadcast in English, the purpose of which is to demonstrate the Chinese vision of the events taking place. The importance of such an international social platform as Twitter is underlined. Most of China's public sector Internet resources lag behind the international level, therefore, it is important to establish a mechanism of action in this area [10]. Under the leadership of the Ministry of Culture of the People's Republic of China, on the basis of relevant interstate agreements, Chinese cultural centers are opened on the territory of foreign countries. The activities of such nonprofit organizations are aimed at promoting the development of bilateral cultural, educational, scientific, technical and other ties. In the Chinese cultural centers various exhibitions are held from time to time i.e. film screenings, literary evenings, book presentations and other events. The active functioning of these centers is visible on the Internet, for example, they send information about various aspects of the life of the Chinese people, invitations to various open events held by the Chinese side are sent. A good tradition of the Ministry of Culture of the People's Republic of China was the holding of cross years of language, culture, tourism, etc. With the support of the Ministry of Culture of the People's Republic of China, numerous events are held in many corners of the Earth. Thus, in October 2009, the project "Chinese Culture Focuses on Africa" was launched in Nigeria, and in 2010, China's Central Television began broadcasting 4 and 9 channels in Nigeria. In May 2012, the cultural center of Nigeria opened its doors in Beijing, and in September 2013 - the Chinese cultural center in the Nigerian capital, Abuja.

In June 2014, China and the Congo signed an agreement on a plan for cultural events for 2014-2016.

In November 2006, Cameroon concluded an agreement with the Chinese side that the state would become a tourist destination for the citizens of the PRC, and in July 2014 an office was opened in Beijing to inform the citizens of Asia on their trips to Cameroon.

In recent years, the demand for Chinese cultural products has increased, its exports amounted to about $\$ 18$ billion in 2013, which is $21 \%$ more than 2012 [11]. Chinese cultural products are exported to approximately 220 states. Popularization of Chinese products on the world market indicates that the cultural and creative trend in China is gradually gaining momentum. In 2012, the Chinese writer Mo Yan received the Nobel Prize in Literature, which allowed the eyes of foreign audiences to be turned to the Chinese cultural market.

\section{HUMANITARIAN ISSUES AS A TOOL OF CHINA'S PUBLIC DIPLOMACY STRATEGY}

However, a number of experts believe that China is not able to compete with the West in this area even in the vastness of Asia, which is due to the fact that the system built by the CCP is not suitable or is difficult to adapt in other states. The model promoted by the leadership of the PRC works extensively, increasing China's influence zones in the world, but the process of adapting Chinese ideas to the territories of other countries is very difficult [12].

Given the increasing presence of the PRC in the territory of African states, China is interested in the formation of an African security architecture, peacekeeping missions, humanitarian issues. Thus, in the period from 2008 to 2015 , in the fight against piracy off the coast of Africa, the Chinese side sent 21 escort detachment to the Gulf of Aden, which secured a safe passage of more than 6,000 merchant ships.

It is worth giving special importance to the emergence of new trends in the foreign policy course of the PRC. China, previously did not attempt to intervene in all sorts of conflicts in the African continent, dispatched 170 combat units of the PLA (People's Liberation Army of China) to the UN peacekeeping mission in Mali [13]. It is noteworthy that the above-mentioned peacekeeping mission was the first when China sent its troops to another state in accordance with the UN mandate. Earlier, the Chinese side also participated in peacekeeping operations, but limited its 
activities by deporting engineers and medical personnel to the emergency zone. Another unprecedented case was Beijing's participation in the conflict in Southern Sudan. Foreign Minister Wang Yi in 2014 urged the parties to immediately cease hostilities and lay down their arms. Wang I also, at the invitation of the Ethiopian side, met with government delegates and rebels in Addis Ababa. Wang Yi during the visit publicly called on the parties to "an immediate cessation of hostilities and violence". However, it is worth paying attention to the fact that the Chinese side imports a considerable amount of oil from Southern Sudan, and, therefore, is concerned about the normalization of the situation in this region. In this regard, there is some discrepancy with the PRC's foreign policy line, since, on the one hand, China advocates non-interference in internal affairs, and, on the other hand, protects its economic interests abroad to ensure its own energy security. At present, Chinese contingents are in the DRC, Western Sahara, Con-d Ivoire, Liberia, Mali, Sudan (Darfur), Southern Sudan. In September 2015, Xi Jinping announced the allocation of \$ 100 million to the African Union as a contribution to the formation of permanent readiness forces at the 2 nd peacekeeping summit held in New York. Also, during the above-mentioned summit, the PRC President spoke in favor of increasing assistance to African states from the world community, he said: "China stands for increased assistance to Africa. After all, peacekeeping operations are mainly conducted in Africa. From a long-term perspective, the international community and the UN need to increase aid to African countries, support them in strengthening and enhancing their security and stability, and to take into account Africa's vision for solving its problems ".

In December 2015, in Johannesburg, during the 6th China-Africa summit, special emphasis was placed on peacekeeping issues.

In February 2016, the People's Republic of China began installation of the first Chinese military base in Africa, to be more precise, in Djibouti for logistical support to the PLA Navy, carrying out anti-piracy, ship protection, peacekeeping and peacekeeping operations in the Gulf of Aden off the coast of Somalia.

It is also worth noting the important role and effectiveness of the Chinese medical teams that operate on the territory of not only the oil-producing states of Africa but also the entire continent. So, in October 2006, China and Angola entered into an agreement to send a medical team to Angola. In January 2012, China and South Sudan signed a memorandum of understanding regarding the sending of medical workers to southern Sudan by the Chinese side. Currently, 33 medical officers carry out the tasks assigned to them in Congo. Currently, China has sent 17 medical brigades totaling 580 people to Cameroon, to Chad - five brigades with 51 employees, to Equatorial Guinea - 27 medical detachments of 483 people.

The most important task facing the leadership of China is to enhance China's role on the international arena, and humanitarian activities in Africa, saturated with interethnic, corruption and other problems, is an excellent platform for the realization of this goal.

\section{CONCLUSION}

Summarizing the above, one can come to the conclusion that humanitarian cooperation, as well as the methods of its implementation for achieving foreign policy goals, have gained more weight for the leadership of the PRC in the new century.

Thus, it should be noted that China for three thousand years of history has learned one important truth, which is that "influence is more important than power." China does not pursue the goal of direct and power domination, the PRC strives for an adjusted and directed influence on the base points of countries, regions and social systems.

\section{REFERENCES}

[1] Zheng B., China's «Peaceful Rise» to Great-Power Status // Foreign Affairs. - October, 2005. - No.4, pp. 18-24

[2] D. Kazarinova, The phenomenon of "soft power" // Free thought. 2011. — №3. - Pp. 187-200.

[3] K. Rudyj, Tools to enhance the influence of China in the world. // Bank Newsletter, 2010, No 2, pp. 41-45.

[4] Trifonov, Foreign policy of the PRC at the present stage. China is the search for harmony. M., 2009, p. 266

[5] O. Borokh, A. Lomanov, From "soft power" to "cultural power" // [Electronic resource] Russia in global politics. December 4, 2012 URL: http://globalaffairs.ru/number/Ot-myagkoi-sily-kkulturnomumoguschestvu-15643 (accessed: September 12, 2017).

[6] S. Luzyanin, M. Mamonov, China in global and regional dimensions. Resources and routes of "elevation" // China in world and regional politics. History and modernity. Issue. XVI: annual publication. / Ed. E.I. Safronov. - Moscow: IFES RAS, 2011, pp. 5-31.

[7] J. Nye, American and Chinese Power after the Financial Crisis // The Washington Quarterly. October 2010, No. 5, pp. 143-153.

[8] Zheng B., China's «Peaceful Rise» to Great-Power Status

[9] Yu. G., Export of Chinese cultural products [Electronic resource] URL: http://mofcom.gov.cn (accessed: 12/09/2017).

[10] Trifonov, Foreign policy of the PRC at the present stage.

[11] D. Mosyakov, New China in the APR // [Electronic resource] RMDC URL: http://russiancouncil.ru/inner/?id_4=725\#top-content (accessed: 12/09/2017).

[12] Yun S., Xi Jinping's Africa Policy: The First Year // [Electronic source] Brookings University. URL: http://www.brookings.edu/blogs/africa-in-focus/posts/2014/04/10jinping-africa-policy-sun (accessed: 12.09.2017).

[13] Ibid. 